Copyright by the American Society of Agricultural and Biological Engineers. Marsh, L. S.; Singh, S., "Economics of greenhouse heating with a mine air-assisted heat pump," Transactions of the ASABE. 37(6): 1959-1963. (doi: 10.13031/2013.28288) @1994

\title{
ECONOMICS OF GREENHOUSE HEATING WITH A Mine AIR-ASSISTED HEAT PUMP
}

\author{
L. S. Marsh, S. Singh
}

\begin{abstract}
An analysis of the economics of greenhouse heating with a heat pump coupled with an inactive deep mine is presented. Several heat pump and conventional gas-fired heater combinations (hybrid systems) were evaluated using a computer model to perform thermal and economic analyses. A $10 \times 30 \mathrm{~m}$, double-polyethylene-covered greenhouse, located in Charleston, West Virginia, was assumed for this analysis. Heat pumps with sufficient capacity to maintain $21^{\circ} \mathrm{C}$ inside the greenhouse for outside temperatures ranging from 0 to $20^{\circ} \mathrm{C}$ (in $2^{\circ}$ degree increments) were modeled. For each heat pump capacity, it was assumed that the additional heat energy required to maintain the specified inside temperature (when outside temperature fell below the heat pump design temperature) was supplied by a natural gas-fired heater. Life-cycle cost analysis was employed to compare greenhouse heating alternatives.

The hybrid system offers lower operating costs than a conventional system for any outside design temperature. However, when initial cost is also considered, the hybrid system has a higher life cycle cost for heat pump design temperatures in the range 0 to $18^{\circ} \mathrm{C}$ and a coefficient of performance (COP) of 3. As the heat pump COP increases beyond 3, the hybrid system becomes economically feasible, showing a lower life cycle cost than a conventional natural gas-fired system. Keywords. Economics, Greenhouse, Heat pump.
\end{abstract}

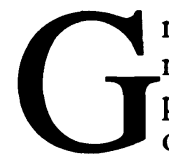
reenhouses require significant energy inputs to maintain an optimum environment for crop production. In fact, for a commercial greenhouse operation, energy costs typically account for 15 to $40 \%$ of plant production costs (Aldrich and Bartok, 1989). The source of this energy is generally driven by economics; coal, fuel oil, and natural gas are commonly employed. The relatively high cost of electricity has historically precluded its use as a fuel for greenhouse space conditioning.

An electric air-to-air heat pump uses a working fluid or refrigerant to absorb heat from one location and carry it to another. The cost per unit of useful heat delivered is much less for a heat pump than for electrical resistance heat. Unfortunately, as the outside air temperature decreases, the amount of heat that can be extracted from the outside air and transferred into the conditioned space also decreases. Also, as the outside air temperature decreases, the heat required to maintain the desired temperature in the heated space increases. During relatively mild periods, a heat pump can deliver three to four times more heat energy (by extracting heat from the outside air) than it uses in electric energy. However, during periods of extreme cold, both the efficiency of an air-to-air heat pump and its output capacity decline dramatically. Figure 1 presents a typical operating

Article was submitted for publication in March 1994; reviewed and approved for publication by the Structures and Environment Div. of ASAE in September 1994.

Supported by the Cooperative State Research Service, USDA, under Project No. 6129640. Mention of brand names by the authors is not intended to serve as an endorsement.

The authors are Lori S. Marsh, ASAE Member Engineer, Assistant Professor, and Sahdev Singh, ASAE Student Member, Graduate Research Assistant, Biological Systems Engineering Dept., Virginia Tech, Blacksburg. curve for an air-to-air heat pump based on product performance data from Carrier Corporation (1989).

Many strategies have been attempted to avoid decreases in both output capacity and operating efficiency of heat pumps that occur due to decreasing ambient temperatures. Two examples of these strategies include: 1) solar-assisted heat pumps that couple the evaporator side of the heat pump with a passive solar collector (Smith, 1984), and 2) earth-coupled or ground-source heat pumps that couple the heat pump to a buried pipe, which acts as a heat exchanger (Bose et al., 1985).

This article addresses the feasibility of coupling the evaporator side of a heat pump with an inactive mine shaft. The U.S. Bureau of Mines reports the existence of over 88,000 inactive or abandoned mines in the United States
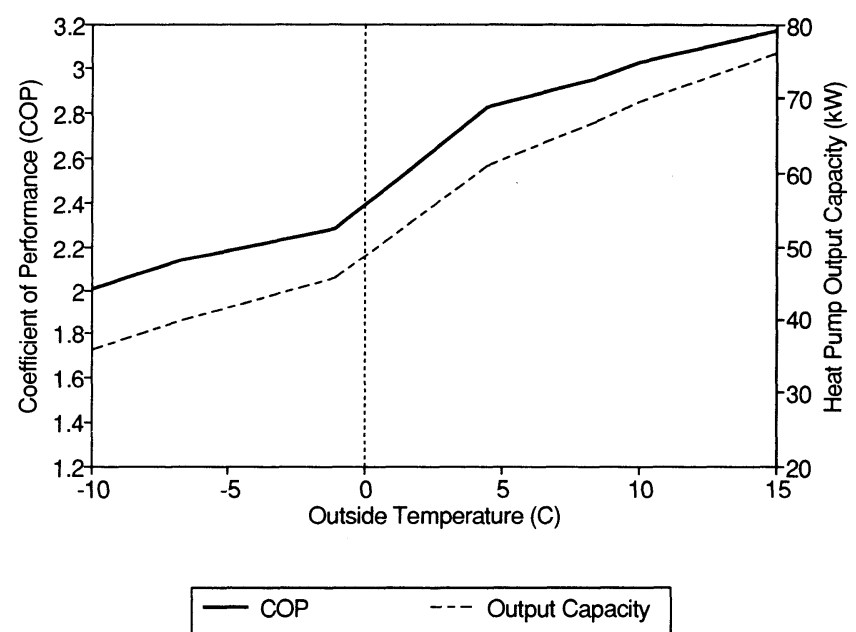

Figure 1-Typical operating curve for a commercial air-to-air heat pump. 
spanning 31 states (Walker et al., 1975). The same report suggests as many as 200,000 inactive mines may exist. The immense surface area of a mine shaft remains at a relatively constant temperature throughout the year. As air is drawn through the mine shaft, it is warmed (or cooled) by the mine shaft walls. The temperature of air drawn from a mine shaft of sufficient length is approximately equal to the long-term average air temperature of the region in which the mine is located (Peterson et al., 1975).

Research conducted by Walker et al. (1975) at the University of Kentucky demonstrated the feasibility of heating a greenhouse by directly ventilating with air drawn from an inactive coal mine. They report energy savings on the order of $87 \%$ of the energy required to heat a conventional greenhouse in the central United States. However, even though heating costs can be dramatically reduced by direct venting of mine air into a greenhouse, other major environmental problems are created. Air exits a mine shaft at or near $100 \%$ relative humidity. When watersaturated air contacts the cold skin of a greenhouse, condensation occurs, which reduces light transmission through the greenhouse glazing, and exposes plants to dripping condensate. Prolonged exposure to high humidity promotes diseases in many crops, reducing crop quality and yield (Buxton et al., 1979). Significant insolation raises greenhouse temperature above the mine air temperature and reduces relative humidity. However, during cloudy periods, direct use of mine air precludes raising the greenhouse air temperature above mine air temperature because any heat added to the greenhouse is lost in the exhausted air.

If mine air is used directly as a heat source, prolonged periods of cloudy weather coincident with cold temperatures result in an environment that is unfavorable to many greenhouse crops. Walker et al. (1975) recognized this problem and proposed, rather than direct use, that mine air be used as a thermal buffer. This concept involves drawing mine air between two glazing materials so that mine air does not enter the plant space. In effect, a greenhouse is constructed within a greenhouse, and mine air is circulated between the two houses. This concept achieves significant reduction in heating costs compared to conventional systems, does not introduce saturated air with its associated disease problems directly into the plant space, and allows heating of the interior production space above mine air temperature. The main disadvantages of this concept are: (1) construction costs are increased, and (2) light transmitted into the growing space is reduced by condensate formation on the interior surface of the outer glazing (during periods of cold weather).

A heat pump appears to have the potential to exploit the economic benefit of constant-temperature mine air without exposing greenhouse crops to the hazards of high humidity and reduced light transmission. The evaporator side of a commercially available, split unit air-to-air heat pump can extract heat from the constant temperature air source available from the mine and transfer it to the greenhouse through the condenser unit. With a constant source of $12^{\circ} \mathrm{C}$ air as found in deep mine shafts in Southwest Virginia (Peterson et al., 1975), a heat pump can achieve a high COP. This scenario reduces energy requirements compared to conventional heating systems, allows the greenhouse air temperature to be elevated above mine air temperature, and does not introduce problems such as high humidity and reduced light transmission.

Coupling a greenhouse with a coal mine shaft offers two distinct operational advantages in addition to a source of heat. These additional advantages are realized by direct use of mine air for greenhouse cooling during hot and/or sunny periods. Problems of light attenuation and disease promotion due to direct use of mine air will not occur during these periods because humidity suppression is achieved by natural solar heating of the mine air within the structure (Buxton et al., 1979). Carbon dioxide $\left(\mathrm{CO}_{2}\right)$ levels in coal mines are generally higher than in ambient air (Peterson et al., 1975). Therefore, direct ventilation with coal mine air results in elevated $\mathrm{CO}_{2}$ levels in the growing space. $\mathrm{CO}_{2}$ is a raw material which, along with water and nutrients, is required for photosynthesis. It is often the limiting factor for plant growth under high light conditions (Aldrich and Bartok, 1989) and is, therefore, an integral component of a high-intensity production system. With a conventional greenhouse cooling system, large volumes of ambient air are moved through the growing space precluding $\mathrm{CO}_{2}$ enrichment; any $\mathrm{CO}_{2}$ added to the greenhouse will be exhausted in the ventilation air. Direct ventilation with mine air also provides superior temperature control (compared to venting with outside air) during periods when the ambient temperature is above the mine-air temperature.

The numerous existing mine shafts in the United States offer a heat source for a heat pump application. One possible method for coupling a greenhouse with an inactive mine is shown in figure 2 . The figure legend describes the operation of this arrangement. Not all inactive mines are attractive candidates for greenhouse heating. Minimum site requirements include an adequate and accessible flat space with a southern exposure and the availability of water and electrical power.

\section{Optimizing Heating System SElEction}

The heating system must be of sufficient capacity to maintain an adequate air temperature within the greenhouse during extreme outside conditions. Typical design conditions allow $15^{\circ} \mathrm{C}$ to be maintained when the outside temperature is $5^{\circ} \mathrm{C}$ below the average minimum temperature (Aldrich and Bartok, 1989). The peak or design load occurs for only a short period each year. When the heating requirement is less than the design load the heating system runs below full capacity or cycles on and off.

While the high efficiency of a mine-coupled heat pump makes it a potentially attractive heat source, two factors make it unlikely that a heat pump alone would represent an economically optimum heating system. First, a heat pump costs significantly more to purchase than a gas-fired heater on a per unit output capacity basis. Second, electricity pricing for commercial customers includes a demand charge (i.e., the utility charges not only for the amount of energy consumed, but also for the rate at which electricity is consumed). The demand charge provides a disincentive to oversize the heat pump system.

To select an economically optimum heating system, the relevant question that a potential investor should ask is, "assuming all systems considered can provide the same 


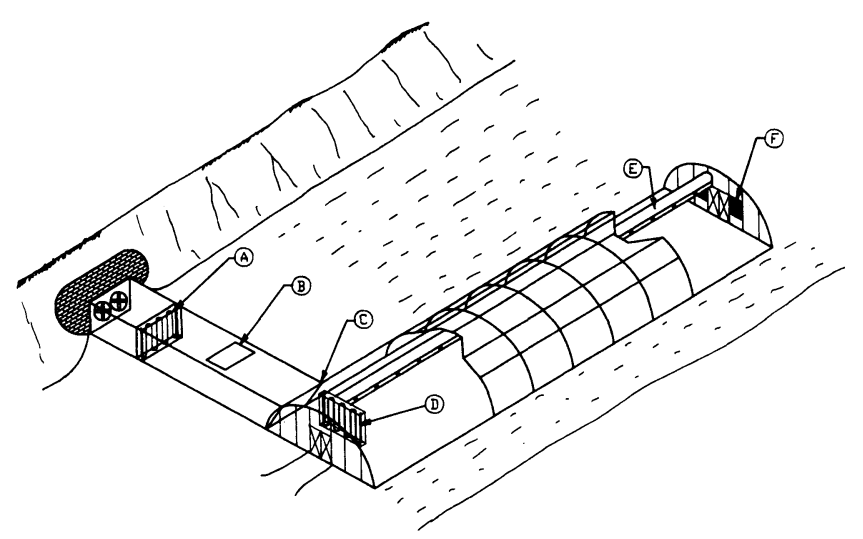

Figure 2-Heat pump coupling with an inactive mine shaft. (A) Evaporator side of heat pump which absorbs heat energy from the mine air. (B) Vent which is open during heat pump operation to exhaust mine air and closed during direct mine air cooling. (C) Vent in greenhouse side wall. This vent is closed during heating and opened for direct mine air cooling. (D) Condenser side of heat pump. A fan (not shown) moves air past condenser coils for greenhouse heating. (E) Perforated polyethylene tube used to distribute warm air the length of the greenhouse. (F) Vents to exhaust ventilation air during direct mine air cooling operation. Closed for heating.

degree of environmental control, which costs the least when all expenses are considered?" To answer this question, the initial cost and operating cost for the systems being considered must be defined.

\section{Thermal Analysis}

A $10 \times 30 \mathrm{~m}$, double-polyethylene-covered greenhouse, located in Charleston, West Virginia, was assumed for this analysis. Total heat energy required annually to maintain $21^{\circ} \mathrm{C}$ during the day (defined as 8:00 A.M. to 6:00 P.M.) and $15^{\circ} \mathrm{C}$ during the night was calculated using a thermal model (Marsh and Albright, 1991). The thermal model, based upon a step-wise steady-state energy balance, determines the amount of the heat energy required for a time step of $1 \mathrm{~h}$.

$$
\mathrm{H}(\mathrm{t})=(\mathrm{U} * \mathrm{~A}) *\left(\mathrm{~T}_{\text {in }}(\mathrm{t})-\mathrm{T}_{\text {out }}(\mathrm{t})\right)-\tau * \mathrm{~b}_{\mathrm{s}} * \mathrm{~S}(\mathrm{t})
$$

where

$$
\begin{aligned}
& \mathrm{H}(\mathrm{t})=\text { heat energy required during hour } \mathrm{t}(\mathrm{kWh}) \\
& \mathrm{U}=\text { heat loss factor including the effects of }
\end{aligned}
$$

If the calculated heat requirement, $\mathrm{H}(\mathrm{t})$, is negative, then $\mathrm{H}(\mathrm{t})$ is set equal to zero. A negative heat requirement indicates the air temperature in the greenhouse is warmer than the set point temperature. Maximum heat pump output for the hour $t$ was calculated as:

$$
H P(t)=U * A *\left(T_{i n}(t)-T_{d}\right)
$$

where $H P(t)$ is the heat pump output and $T_{d}$ is the heat pump design temperature. Heat pumps with sufficient capacity to maintain $21^{\circ} \mathrm{C}$ inside the greenhouse for heat pump design temperatures ranging from 0 to $20^{\circ} \mathrm{C}$ (in $2^{\circ}$ increments) were modeled. For each heat pump capacity, it was assumed that additional heat energy required to maintain the specified inside temperature (when outside temperatures fell below the heat pump design temperature) was supplied by a gas-fired heater. If $H(t)$ is smaller than $H P(t)$, then the entire heat energy requirement during the hour $t$ is provided by the heat pump. In a case when the requirement is larger than the maximum heat pump output, the difference $[\mathrm{H}(\mathrm{t})-\mathrm{HP}(\mathrm{t})]$ is supplied by the gas-heater.

The model requires weather data and parameters describing the thermal properties of the greenhouse. Twenty-five years of hourly observations of air temperature and solar radiation for Charleston, West Virginia, were generated using a model developed by Richardson and Wright (1984). The 25 years of hourly observations were averaged to produce a test-year data set representative of average temperature $\left(\mathrm{T}_{\text {out }}\right)$ and average solar radiation (S) in Charleston.

Since the heat pump would be extracting heat from a constant temperature source (an inactive mine), the COP remains effectively constant. Based upon product literature from Carrier Corporation (1989), the COP of commercial air-to-air heat pumps varies from 2 to a little over 3 depending upon the heat pump source temperature (fig. 1). For an input air temperature of $12^{\circ} \mathrm{C}$, a COP of 3 was selected. It was assumed that gas-fired heaters would achieve an $80 \%$ operating efficiency. The values of model parameters used in the analysis are shown in table 1.

Heat energy supplied to the greenhouse (expressed per meter squared of greenhouse floor area) by both heat pump and gas-fired heaters, as a function of heat pump design temperature, is shown in figure 3 . The double-

Table 1. Values of parameters used in thermal and economic analyses

\begin{tabular}{llc}
\hline Parameter & Unit & Value \\
\hline Greenhouse dimensions & $\mathrm{m}$ & $10 \times 30$ \\
Heat loss factor $(\mathrm{U})$ & $\mathrm{W} / \mathrm{m}^{2} . \mathrm{K}$ & 5 \\
Greenhouse set temperatures $\left(\mathrm{T}_{\mathrm{in}}\right)$ & $\mathrm{C}$ & 21 (daytime) \\
& & 15 (nighttime) \\
Mine air temperature & $\mathrm{C}$ & 12 \\
Heat pump design temperature $\left(\mathrm{T}_{\mathrm{d}}\right)$ & $\mathrm{C}$ & 0 to 20 \\
& & $\left(2^{\circ}\right.$ increment) \\
Gas-heater design temperature & & -10 \\
Marginal tax rate & percent & 20 \\
Expected annual inflation rate & percent & 4 \\
After-tax time value of money & percent & 7 \\
Heat pump cost & $\$ / \mathrm{kW}$ & 313 \\
Gas-fired heater cost & $\$ / \mathrm{kW}$ & 40 \\
Demand charge & $\$ / \mathrm{kW}-$ month & 3.22 \\
Electricity charge & $\$ / \mathrm{kWh}$ & 0.0405 \\
Cost of natural gas & $\$ / \mathrm{kWh}$ & 0.017 \\
Heat pump COP & - & 3 \\
Gas-heater efficiency & percent & 80 \\
\hline
\end{tabular}




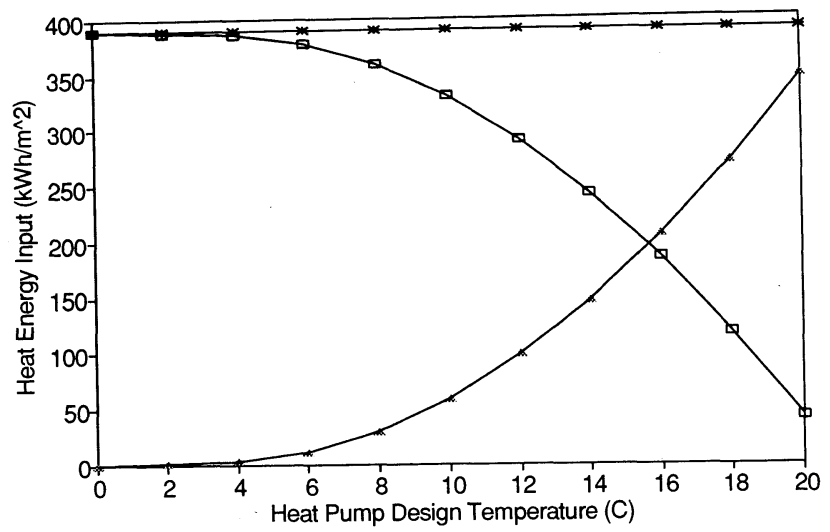

$\because$ Heat Pump $\longrightarrow$ Gas-fired Heater $\cdots$ Total Energy

Figure 3-Heat energy input to greenhouse from heat pump and gasfired heater.

polyethylene-covered greenhouse modeled requires $390 \mathrm{kWh} / \mathrm{y}$ of heat energy per meter squared of floor area to maintain the specified inside temperatures. As the heat pump design temperature rises, the contribution of the gasfired heater increases.

Figure 4 considers the operating efficiencies of heat pump and gas-fired heater and presents the commercial energy inputs (electricity and natural gas) required to maintain desired temperatures as a function of heat pump design temperature. For all design temperatures, the required commercial energy input is less than the heat energy required by the greenhouse. This is due to the COP of the heat pump, which allows it to deliver three units of heat to the greenhouse for each unit of commercial heat input. The lower the heat pump design temperature, the less the commercial heat requirement for the greenhouse.

\section{ECONOMic ANALYsis}

For each hybrid system, it was necessary to consider the electric demand charge corresponding to the input energy requirement of the heat pump. It was assumed that the heat pump would operate 11 months per year; the monthly

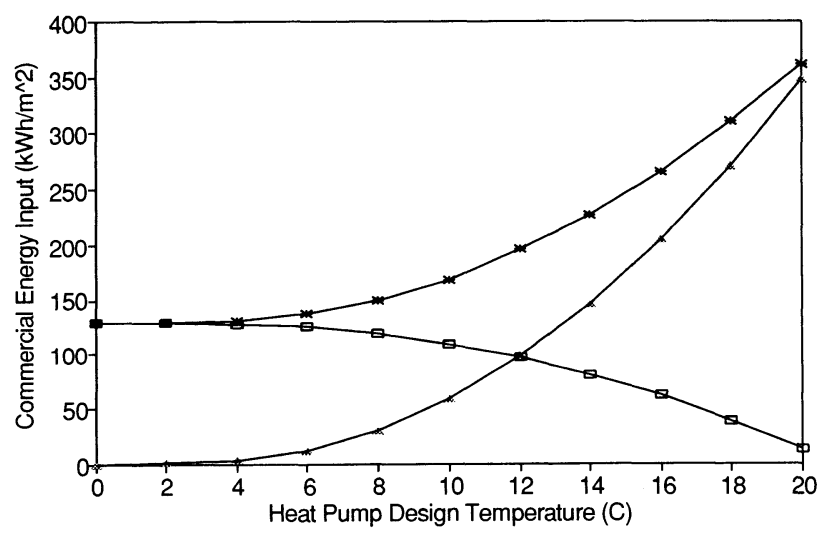

$\rightarrow$ Heat Pump $\rightarrow$ Gas-fired Heater $\rightarrow$ Total Energy

Figure 4-Commercial energy input to heat pump and gas-fired heater. demand charge multiplied by 11 yielded the annual demand charge, which was added to the annual operating cost of the system. The demand charge plus the actual energy charge for both the heat pump and the auxiliary gas-fired heater yielded the total operating cost. Figure 5 displays annual heating cost as a function of heat pump design temperature based upon current energy prices shown in table 1 . A heat pump design temperature of $8^{\circ} \mathrm{C}$ corresponds to the system with the least operating cost $\left(\$ 5.38 / \mathrm{m}^{2}\right)$. For all heat pump design temperatures up to $20^{\circ} \mathrm{C}$, the annual operating cost of the hybrid system is lower than that of a conventional gas-fired heating system $\left(\$ 6.61 / \mathrm{m}^{2}\right)$.

The difference between conventional and hybrid system costs shown in figure 5 represents the saving in annual operating cost due to heat pump installation. However, the equipment costs for the different systems have not been considered. To account for equipment cost, a life-cycle cost analysis was employed. System costs were computed over the useful life of the equipment using a discounted cash flow technique. By discounting future dollars the analysis incorporates the time value of money concept-a dollar held today is worth more than a dollar promised in the future. Thus, discounting cash flows by the time value of money is useful to compare alternate systems where operating costs, which occur in future years, are a major component of the system cost.

A greenhouse supply company was consulted for current prices of gas-fired greenhouse heaters (Wetsel, 1993). A heating, ventilation, and air conditioning contractor was consulted to assign a price to heat pumps. Heat pumps and gas-fired heaters come in discrete sizes; they are not available as a continuum. However, for ease of analysis, it was assumed that an infinite array of sizes was available. In practice, a commercially available size nearest to the theoretically optimum size would be recommended. Based on cost data from Wetsel Seed Company (1993) and Blue Ridge Heating and Air, Inc. (personal communication), initial costs (including installation costs) of $\$ 40 / \mathrm{kW}$ capacity for the gas-fired heater and $\$ 313 / \mathrm{kW}$ capacity for the heat pump were assigned. For the assumed greenhouse and design conditions, heat pump capacity varies from $0.059 \mathrm{~kW} / \mathrm{m}^{2}$ of greenhouse floor area for a design

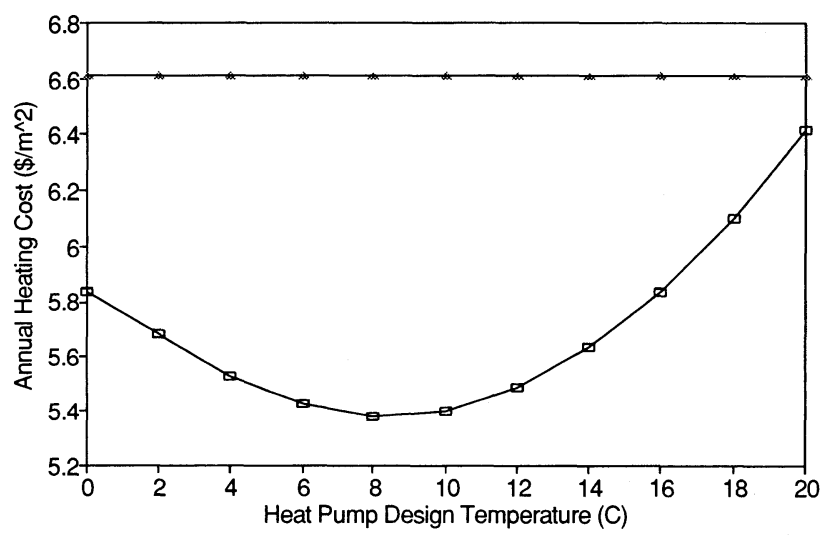

$\because$ Hybrid System Conventional System

Figure 5-Annual heating cost for hybrid (heat pump and gas-fired heater) and conventional gas-fired heater. 
temperature of $0^{\circ} \mathrm{C}$ to $0.003 \mathrm{~kW} / \mathrm{m}^{2}$ of greenhouse floor area for a design temperature of $20^{\circ} \mathrm{C}$. The conventional system has an initial investment of $\$ 12.9 / \mathrm{m}^{2}$. The initial investment for a hybrid system varies from $\$ 59.1 / \mathrm{m}^{2}$ at $0^{\circ}$ $\mathrm{C}$ outside design temperature to $\$ 15.1 / \mathrm{m}^{2}$ at $20^{\circ} \mathrm{C}$ outside design temperature. It was assumed that all heating systems were purchased outright in year zero, had an expected life of 15 years (ARI, 1991), and had no salvage value at the end of 15 years.

Results of the life-cycle cost analysis are presented in figure 6 . The financial parameters used in this analysis were tax rate of the firm (20\%), average inflation rate (4\%), and time value of money (7\%). The life-cycle cost of the conventional system is $\$ 82.00 / \mathrm{m}^{2}$ as shown by the horizontal line. Figure 6 demonstrates that when initial and annual operating costs are considered, the heat pump/gasfired heater combinations with heat pump design temperatures in the range $0^{\circ}$ to $18^{\circ} \mathrm{C}$ and heat pump COP of 3 (Hybrid System HCOP3.0) have higher life-cycle costs than the conventional system. Economically, the hybrid system performs equally well or marginally better than the conventional system only when the outside design temperature for the heat pump is in the range $18^{\circ}$ to $20^{\circ} \mathrm{C}$. Two alternative hybrid systems, one with COP of 3.25 (HCOP3.25) and the other with COP of 3.50 (HCOP3.5), were also considered in the analysis. Increasing the heat pump COP makes the heat pump/gas-fired heater combinations with $14^{\circ} \mathrm{C}$ (for HCOP3.25) and $10^{\circ} \mathrm{C}$ (for HCOP3.5) or higher outside design temperature more economical than the conventional system (fig. 6). Economics are improved because the increase in heat pump COP lowers the annual operating cost of the hybrid system. To make a heat pump-assisted heating system economically attractive in comparison to a conventional gas-fired system, one or more of the following must occur: a lower initial cost for the heat pump relative to the alternative system; a less expensive electrical rate structure including a lower energy charge and/or a lower electrical demand charge; or a higher rate structure for natural gas.

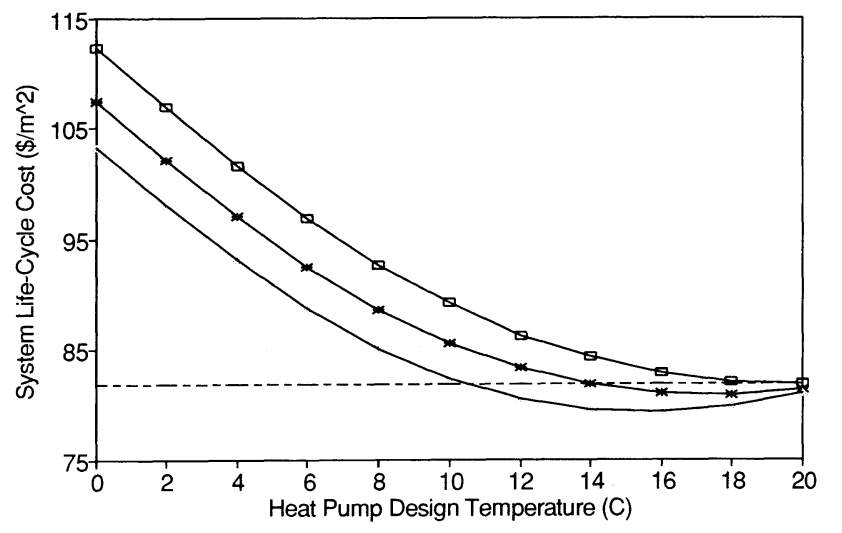

--- Conv. Sys. $\rightarrow-$ HCOP3.00 $\rightarrow$ HCOP3.25 - HCOP3.50

Figure 6-Life-cycle cost analysis for alternative heating systems.

\section{CONCLUSIONS}

A heat pump's high initial cost (compared to a gas-fired heater) precludes purchasing a high capacity heat pump to take advantage of fuel cost savings that occur only a small percentage of the year. This analysis indicates that a heat pump coupled with an inactive mine shaft is an economically viable alternative to a natural gas-fired heating system provided the heat pump is highly efficient (COP of 3.5 or greater) and sized to satisfy the heating load for $10^{\circ} \mathrm{C}$ or higher outside temperatures. The heat pump, which has a higher initial cost, but lower operating cost compared to the gas-fired system, must operate enough hours each year to justify its initial cost. This is accomplished by sizing the heat pump to carry a base load, that is, to provide the first $5^{\circ} \mathrm{C}$ boost above ambient temperatures. Additional heating requirements are satisfied by the natural gas-fired heater.

While this analysis was applied to a greenhouse scenario, the economics for any space-heating application should be similar. Also, it should be noted that any readily available, virtually free source of heat, such as warm waste water, groundwater, or heat from the ground (via a heat exchanger) can offer similar economic advantages for heat pump applications over natural gas-fired systems.

\section{REFERENCES}

Aldrich, R. A. and J. W. Bartok. 1989. Greenhouse Engineering, 137. Northeast Regional Agricultural Engineering Service, Ithaca, N.Y.

Air-Conditioning \& Refrigeration Inst. 1991. HVAC Applications. Arlington, Va.: ARI.

Bose, J. E., J. D. Parker and F. C. McQuiston. 1985. Design/Data Manual for Closed-Loop Ground-Coupled Heat Pump Systems, Atlanta, Ga.: ASHRAE.

Buxton, J. W., J. N. Walker, L. D. Collins, D. E. Knavel and J. R. Hartman. 1979. Crop response in a greenhouse environmentally controlled with air drawn from a coal mine. J. Am. Soc. Hortic. Sci. 104(5):696-698.

Carrier Corporation. 1989. Product information. Form 38AQ, BQ1PD, 14-18, Syracuse, N.Y.

Marsh, L. S. and L. D. Albright. 1991. Economically optimum day temperatures for greenhouse hydroponic lettuce production. Part I: A computer model. Transactions of the ASAE (34):2:550-556.

Peterson, W. O., J. N. Walker, G. A. Duncan and D. T. Anastasi. 1975. Composition of coal mine air in relationship to greenhouse environment control. Transactions of the ASAE 18:(1):140-144.

Richardson, C. W. and D. A. Wright. 1984. WGEN: A model for generating daily weather variables. Washington, D.C.: USDAARS.

Smith, N. 1984. Solar-assisted heat pumps for space heating in a cold climate. Agricultural Engineering 65(July):14-18.

Walker, J. N. and J. W. Buxton. 1977. Can circulating air through a buried pipe be used to heat and cool greenhouses? J. Am. Soc. Hortic. Sci. 102(5):626-629.

Walker, J. N., W. O. Peterson, G. A. Duncan and D. T. Anastasi. 1975. Temperature and humidity in a greenhouse ventilated with coal mine air. Transactions of the ASAE 19:311-317.

Wetsel Seed Company, Inc. 1993. Supplies for the grower, 150. Harrisonburg, Va. 